\title{
THERMOPHYSICAL AND MECHANICAL PROPERTIES OF COMPRESSED EARTH BLOCKS CONTAINING FIBRES: BY-PRODUCT OF OKRA PLANT AND POLYMER WASTE
}

\author{
PHILBERT NSHIMIYIMANA ${ }^{1,2}$, CÉSAIRE HEMA ${ }^{1,3}$, OUSMANE ZOUNGRANA ${ }^{1,4}$, \\ ADAMAH MESSAN ${ }^{1} \&$ LUC COURARD ${ }^{2}$ \\ ${ }^{1}$ Laboratoire Eco-Matériaux et Habitats Durables (LEMHaD), \\ Institut International d'Ingénierie de l'Eau et de 1'Environnement (Institut 2iE), Burkina Faso \\ ${ }^{2}$ Urban and Environmental Engineering (UEE), Université de Liège (ULiege), Belgium \\ ${ }^{3}$ Architecture et Climat, Université Catholique de Louvain (UCLouvain), Belgium \\ ${ }^{4}$ Service Socio-Anthropologie du Développement, Université de Liège (ULiège), Belgium
}

\begin{abstract}
Municipal wastes such as water sachets and agricultural by-products in Burkina Faso need proper management to limit their hazards to the environment. This study investigated the effect of incorporation of fibres from agricultural by-products (okra plant fibre) and water sachet wastes (polymer fibre) on thermophysical and mechanical properties of stabilized compressed earth blocks (CEBs). The CEBs were moulded from moistened mixtures of clayey earthen material stabilized with $10 \mathrm{wt} . \%$ CCR (calcium carbide residue) and incorporated with 0 to $1.2 \mathrm{wt} . \%$ fibre of each type. The CEBs were cured in a closed environment, at room temperature in the lab $\left(30 \pm 5^{\circ} \mathrm{C}\right)$ for 45 days. Cured CEBs were dried $\left(40 \pm 2{ }^{\circ} \mathrm{C}\right)$ and tested for the thermophysical and mechanical properties. The experimental results showed that the average bulk density of CEBs decreased in the range of 1690$1565 \mathrm{~kg} / \mathrm{m}^{3}$ with the incorporation of $0-1.2 \%$ fibre. The thermal conductivity and diffusivity also decreased, respectively, in the ranges of 0.84 to $0.63 \mathrm{~W} / \mathrm{m} . \mathrm{K}$ and $6.1 \mathrm{E}-7$ to $4.2 \mathrm{E}-7 \mathrm{~m}^{2} / \mathrm{s}$ with plant fibres and 0.84 to $0.38 \mathrm{~W} / \mathrm{m} . \mathrm{K}$ and $54 \mathrm{E}-7$ to $2.3 \mathrm{E}-7 \mathrm{~m} / \mathrm{s}$ with polymer fibres. This resulted in evolution of the depth of penetration of the thermal flux from 0.12 to $0.07 \mathrm{~m}$ which is smaller than the total thickness of the CEBs $(0.14 \mathrm{~m})$. This shows the improvement of the thermal performance of the CEBs incorporated with fibres in the context of the warm climate of Burkina Faso. However, the dry and wet compressive strength respectively decreased from 4.3 to $2.9 \mathrm{MPa}$ and 2.7 to $1.3 \mathrm{MPa}$, which were respectively greater than 2 and $1 \mathrm{MPa}$ required for the construction of non-load bearing buildings. These results suggest that CEBs containing by-product fibres are useful to improve the thermal efficiency of one-storey building.
\end{abstract}

Keywords: bulk density, compressed earth block, compressive strength, thermal property, by-product fibre.

\section{INTRODUCTION}

The incorporation of fibres in earthen materials is traditionally practised to improve their performance in building construction. The most recent scientific studies of the effects of fibres on the earthen materials have been mainly carried out on the physical and mechanical properties of adobe/mud bricks [1], [2], extruded or compressed earth blocks (CEBs) [3]-[9] and rarely on the hygrothermal properties and durability of CEBs [5], [9]-[11]. However, if CEBs, the modern technique of earth-based building construction [12], are to be used in the warm Sahelian region such as Burkina Faso; it is essential to understand their thermophysical properties and ways for their improvement for taking full advantages of their potential to regulate the hygrothermal and energy performance of buildings [13], [14].

Fibres from non-conventional origins such as plants or other by-products are interesting for improving the properties and environmental impact of CEBs, given that they are from renewable or secondary resources [10], [11], [15]. The secondary resources present potential in terms of recycling or reuse for reducing the consumption of natural resources and 
environmental hazards [10]. Plant fibres have recently been used to improve the properties of earth blocks [4], [9], [10], [16], [17]. Additional attempts have been previously made to reuse solid wastes for reinforcement of soil blocks as part of waste management [18]-[20].

Prasad et al. [18] reported that $20 \mathrm{~mm}$ long fibres, chopped from carry bags and water bottles, improved the ductility of pressed soil blocks, with limited improvement of the compressive strength. Villamizar et al. [19] also observed a limited effect of cassava peels on the improvement of the compressive strength of stabilized CEBs. Elenga et al. [20] reported that $20 \mathrm{~mm}$ long fibres from post-consumer polyethylene waste slightly increased the compressive strength of CEBs. This suggests that the effects of fibres from secondary resources on earthen materials should not only be assessed on the mechanical performances, but also others properties such as thermal properties.

Moreover, various studies assessed the influence of the fibre size and content on the performances of earthen materials. The majority of the studies used the length between $10 \mathrm{~mm}$ and $50 \mathrm{~mm}$ [10]. Laibi et al. [21] reported that the thermal conductivity of CEBs decreased with increasing the length $(10-30 \mathrm{~mm})$ of $1.2 \mathrm{wt} \% \%$ kenaf fibres. Millogo et al. [17] reported a similar observation for adobes. Danso et al. [22] reported that coconut, bagasse and palm fibres which respectively have the length of $50 \mathrm{~mm}, 80 \mathrm{~mm}$ and $38 \mathrm{~mm}$ produced blocks which have the maximum compressive strength. Danso et al. [9] also reported difference in the compressive strength from the three types of fibres, reaching the optimum with $0.25-0.5 \%$ fibre content.

In fact, the $50 \mathrm{~mm}$ long fibre $(0.35 \mathrm{wt} \%)$ produced higher tensile and compressive strength compared to the $25 \mathrm{~mm}$ long fibre. This was due to the insufficient embedded length (25 mm) to develop full tensile capacity [23]. Prasad et al. [18] reported that $0.1 \%$ fibre gave higher density and wet compressive strength than $0.2 \%$ for the $20 \mathrm{~mm}$ long fibre. This was related to the heterogeneous distribution of high content $(0.2 \%)$ of fibres. Long fibres also do not produce homogenous mixtures, they have dispersion (workability) problems [24]. Therefore, short fibres are preferable for mixing homogeneity, but may result in lower mechanical performances than long fibres. Increasing the length and content of fibre may respectively increase the strength and decrease the thermal conductivity, but also compromise the homogeneity and stability of the mixtures.

In order to counteract the likely decrease of the compressive strength, various studies incorporated fibres in matrix of earth stabilized with chemical binders, such as cement, lime, organic or geopolymer [3], [10]. However, the incorporation of $0-0.2 \%$ date palm fibre still decreased the compressive strength of CEBs stabilized with $8 \%$ lime, but improved the thermal conductivity [5]. Instead of the cement or lime, by-product binders such as calcium carbide residue (CCR) can be useful for the stabilization and improvement of the thermal and mechanical properties of CEBs [13], [25], [26]. Therefore, the CCR was used for the stabilization of CEBs prior to the incorporation of fibres.

Furthermore, okra bast fibres are interesting plant fibres that may be useful for the reinforcement of the earthen matrix. Okra plant, also known as gombo or ladies fingers (Abelmoschus/ Hibiscus esculentus) depending on the geographical location, is a 2-4 m tall plant and mostly grown in warm regions of West Africa (Burkina Faso), India, etc., for its dietary values [27]. The earliest scientific study of okra fibre is traced back in 2007, "Chemical analysis of okra bast fibre (Abelmoschus esculentus) and its physico-chemical properties" [28]. Since then, the studies of okra fibres have multiplied (more than 40 citations of [28] on Google Scholar as at 27 March 2020) on their treatments and characteristics [27], [29], applications mainly in polymer based composites [29], [30], textiles [31] and as a potential insulation material [32]. This is mainly due to the high tensile strength of bast fibres compared to other natural fibres. To the best knowledge of the authors, okra fibres were never 
before incorporated in earthen materials. The authors also did not encounter any scientific report on the reuse of the wastes from water sachets which cause environmental plague in Burkina Faso [33].

Thus, the present study attempts to reuse and add value to okra bast fibres and water sachets respectively from the agricultural by-product and municipal waste in Burkina Faso. The fibres of length of $30 \mathrm{~mm}$ and content in the range of $0-1.2 \mathrm{wt} . \%$ were incorporated in the matrix of CEBs stabilized with CCR (10 wt.\%). The study aims to assess the effects of fibres from the secondary resources on the thermophysical as well as mechanical properties of CEBs for applications in building construction.

\section{MATERIALS AND EXPERIMENTAL METHODS}

\subsection{Processing and characteristics of raw materials}

The matrix of CEBs is produced from a kaolinite-rich earthen material stabilized with calcium carbide residue (CCR). The earthen material and CCR were respectively collected from Kamboinse $\left(12^{\circ} 29024.4800 \mathrm{~N}, 1^{\circ} 32059.2800 \mathrm{~W}\right.$, altitude $\left.326 \mathrm{~m}\right)$ and Kossodo $\left(12^{\circ} 25.9350 \mathrm{~N}, 001^{\circ} 29.3740 \mathrm{~W}\right.$, altitude $\left.301 \mathrm{~m}\right)$ in the vicinity of Ouagadougou, Burkina Faso. The physico-chemical and mineral characteristics of these materials were reported in previous studies [25], [34]. The earthen material is a silt-clay of medium to high plasticity (plasticity index: 10-25 and liquidity limit: 40-65). It contains $10-25 \%$ clay particles $(<0.2 \mu \mathrm{m})$ and mainly $45-75 \%$ kaolinite and only $5-40 \%$ quartz minerals [34]. The CCR is an industrial by-product from the production of acetylene gas by hydrolysis of calcium carbide. The CCR is finer than $125 \mu \mathrm{m}$, after grinding and sieving, and contains up to $40 \%$ portlandite (hydrated lime: $\mathrm{Ca}\left(\mathrm{OH}_{2}\right)$ ). The specific density of the earthen material and $\mathrm{CCR}$ are respectively 2.75 and 2.49. The BET specific surface area of the CCR is $14 \mathrm{~m}^{2} / \mathrm{g}$ [25].

The plant and polymer fibres were incorporated in the matrix of CEBs. The plant fibres were extracted from the skin of the stem of okra plant collected from Kaya (100 km north of Ouagadougou). The skin was soaked in tap water for 3-4 weeks to allow the decomposition of undesired organic matters, then manually leached and washed multiple times until water turns clean and sun dried (Fig. 1(a)). The polymer fibres were extracted from water sachets collected from municipal waste in Ouagadougou. The sachets were properly washed and sliced into $\pm 5 \mathrm{~mm}$ large fibres (Fig. 1(b)). Both fibres were cut into $30 \mathrm{~mm}$ long before incorporation in the matrix.

The tensile strength was tested on at least 10 single fibres selected randomly from each type of fibres. The test was carried out on a gauge length of $30 \mathrm{~mm}$ at loading speed of

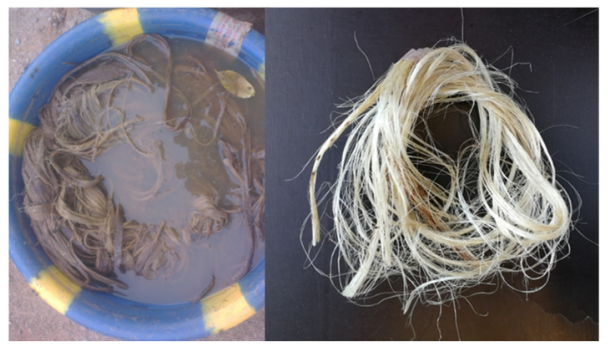

(a)

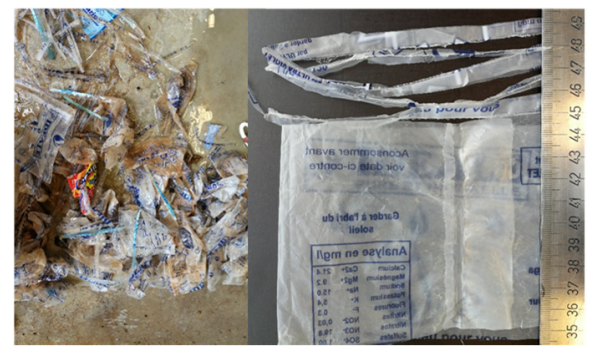

(b)

Figure 1: Fibres from (a) Okra plants; and (b) Water sachets. Raw (left) versus processed (right). 
$1 \mathrm{~mm} / \mathrm{min}$, using a tensile testing machine of the Zwick Roell whose cell has maximum capacity of $10 \mathrm{~N}$. The average tensile strength and maximum strain to failure are respectively $346 \pm 197 \mathrm{MPa}$ and $2.2 \pm 0.6 \%$ for plant fibres and $2.08 \pm 0.31 \mathrm{MPa}$ and $450 \pm 53 \%$ for polymer fibres. The specific density and absorption were also determined using water pycnometer and water saturation. The specific density is 1.09 and 0.99 respectively for plant and polymer fibres. The water absorption at saturation ( 24 hours) is $364 \pm 16 \%$ for plant fibres and was not determined for polymer fibres. The okra fibres are stronger than banana fibres (25-289 MPa) [7], but less strong than kenaf fibres (1,000 $\pm 250 \mathrm{MPa})$ [1] which were previously incorporated in earth blocks. In fact, the more cellulose the plant fibre contains, the stronger it is. While the okra fibres were previously reported to contain $60-70 \%$ cellulose [27], the banana fibres contain $48-59 \%$ cellulose [7] and kenaf fibres contain $70 \%$ cellulose [1].

\subsection{Production and characterization of CEBs}

Each of the fibre types, plant and polymer, was added in content of $0-1.2 \mathrm{wt} . \%$ of the matrix and thoroughly mixed. The matrix mixture was produced with dry earthen material and 10 wt.\% CCR of the earth. The optimum moisture content (19\%) of matrix mixture, determined by static compaction referring to [35], was added to the dry mixtures of matrix and fibres. The wet mixtures were compressed in a mould $\left(295 \times 140 \times 95 \mathrm{~mm}^{3}\right)$ of terstaram machine at normal pressure estimated at 3.5 MPa to produce stabilized CEBs. The stabilized CEBs were covered, in order to prevent the loss of moisture and minimize the carbonation, and cured at ambient temperature in the lab $\left(30 \pm 5^{\circ} \mathrm{C}\right)$ for 45 days. Previous studies [13], [36] suggested that in these conditions, the mixture of the earthen material and $10 \% \mathrm{CCR}$ undergoes effective pozzolanic reaction to produce stabilized CEBs with improved mechanical and thermal properties. Cured CEBs were dried at $40 \pm 2{ }^{\circ} \mathrm{C}$ until reaching constant mass (variation of mass less than $0.1 \%$ in 24 hours) before testing their properties

$$
\begin{gathered}
\rho_{\mathrm{b}}=\operatorname{Mdx} \rho_{\mathrm{wt}} /(\text { Msat. air }- \text { Msat. wt }), \\
\mathrm{TP}=100 \times\left(1-\rho_{\mathrm{b}}\right) / \rho_{s}, \\
\mathrm{WA}=100 \mathrm{x}(\text { Msat. air }-\mathrm{Md}) / \mathrm{Md}, \\
\mathrm{Ca}_{10 \text { min }}=100 \mathrm{x}\left(\mathrm{M}_{10 \text { min }}-\mathrm{Md}\right) /(1000 \mathrm{xSx} \sqrt{10}), \\
\mathrm{R}_{\mathrm{c}}=10 \times \mathrm{xF}_{\mathrm{r}} / \mathrm{S} .
\end{gathered}
$$

The thermophysical and mechanical properties of CEBs were tested on dry specimen which has mass, $\mathrm{Md}(\mathrm{kg})$. Bulk density, $\rho\left(\mathrm{kg} / \mathrm{m}^{3}\right)$, was determined using eqn (1) after hydraulic weighing [37]. Msat.wt $(\mathrm{kg})$ and Msat.air $(\mathrm{kg})$ are the mass of the specimens after 24 hours of water saturation respectively weighed in water and in air; $\rho_{\mathrm{wt}}\left(1,000 \mathrm{~kg} / \mathrm{m}^{3}\right)$ is the density of water. The total porosity, TP (\%), was estimated form the ratio of the bulk density, $\rho_{\mathrm{b}}$, of CEBs and the equivalent specific density, $\rho_{\mathrm{s}}$, of constituting particles, using eqn (2). The water absorption, WA (\%), after saturation was determined using eqn (3). The coefficient of capillary absorption, $\mathrm{Ca}_{10 \min }\left(\mathrm{g} / \mathrm{cm}^{2} \cdot \mathrm{min}^{1 / 2}\right)$, was determined using eqn (4), referring to XP P13-901 standard [38]. $\mathrm{M}_{10 \mathrm{~min}}(\mathrm{~kg})$ is the mass of specimen after 10 minutes of capillary absorption through the laying face of area, $\mathrm{S}\left(29.5 \times 14 \mathrm{~cm}^{2}\right)$. The compressive strength was tested, in dry and wet conditions after immersion in water for 2 hours. It was tested using a hydraulic press equipped with a load cell of $300 \mathrm{kN}$ maximum capacity, at loading speed of $0.2 \mathrm{~mm} / \mathrm{s}$, referring to XP P13-901 standard [38]. The compressive strength, Rc (MPa), was 
calculated in eqn (5); $\mathrm{Fr}(\mathrm{kN})$ is the maximum load at failure and $\mathrm{S}\left(\mathrm{cm}^{2}\right)$ is the applied surface.

Thermal properties were independently measured on the specimen which has a size of $6 \times 4 \times 3 \mathrm{~cm}^{3}$ for the thermal effusivity, $\mathrm{E}\left(\mathrm{J} / \mathrm{m}^{2} \cdot \mathrm{K} \cdot \mathrm{s}^{1 / 2}\right)$ and $6 \times 4 \times 1 \mathrm{~cm}^{3}$ for the volumetric thermal capacity, $\mathrm{Cp}\left(\mathrm{J} / \mathrm{m}^{3} . \mathrm{K}\right)$. The specific heat capacity $(\mathrm{J} / \mathrm{kg} . \mathrm{K})$ was determined from the volumetric thermal capacity $\left(\mathrm{J} / \mathrm{m}^{3} . \mathrm{K}\right)$ and bulk density, $\rho\left(\mathrm{kg} / \mathrm{m}^{3}\right)$ of CEBs. The thermal conductivity, $\lambda(\mathrm{W} / \mathrm{m} . \mathrm{K})$, thermal diffusivity, a $\left(\mathrm{m}^{2} / \mathrm{s}\right)$, and thermal penetration depth, $\delta_{\mathrm{p}}(\mathrm{m})$, were respectively determined using eqns (6)-(8). This assumes a semi-infinite medium and harmonic variation of thermal signal over a period, $\mathrm{T}(\mathrm{s})$, of 24 hours $(86,400$ seconds)

$$
\begin{aligned}
\lambda & =\mathrm{E}^{2} /(\mathrm{Cp}), \\
\mathrm{a} & =\lambda /(\mathrm{Cp}), \\
\delta_{\mathrm{p}} & =\sqrt{(\mathrm{axT} / \pi)} .
\end{aligned}
$$

\section{RESULTS AND DISCUSSION}

\subsection{Bulk density, porosity and water absorption}

Fig. 2 presents the evolution of bulk density and total porosity of CEBs containing fibres. The incorporation of $0-1.2 \%$ fibres in the matrix of CEBs stabilized with $10 \%$ CCR resulted in the decrease of bulk density in the range of 1,690 to $1,610 \mathrm{~kg} / \mathrm{m}^{3}$ with plant fibres and 1,690 to $1,565 \mathrm{~kg} / \mathrm{m}^{3}$ with polymer fibres (Fig. 2(a)). This is accompanied by the evolution of total porosity in the range of 38 to $40 \%$ with plant and 38 to $42 \%$ with polymer fibres (Fig. 2(b)). Furthermore, Fig. 2 shows that the bulk density and porosity of CEBs containing polymer fibres have higher discrepancy (standard deviation) than the CEBs containing plant fibres. This can be related to the difficulty of achieving homogeneous mixtures with polymer fibres. However, Fig. 2 shows the achievement of lightening effect with both types of fibres. This is one of the aims of the incorporation of plant aggregates/fibres in the earthen materials [10].

Guettala et al. [39] also reported decreasing value of bulk density $\left(1,710-1,670 \mathrm{~kg} / \mathrm{m}^{3}\right)$ with increasing content of cock granules $(0-12 \%)$ for CEBs stabilized with $12 \%$ cement.

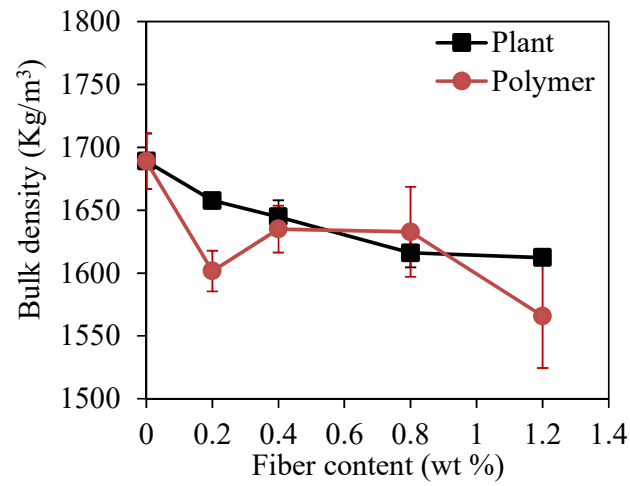

(a)

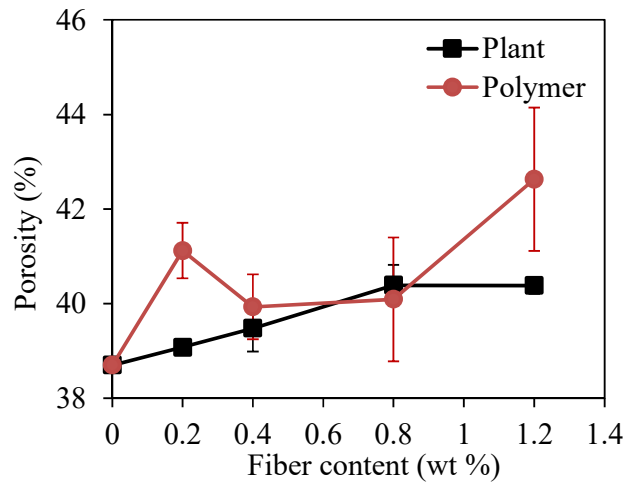

(b)

Figure 2: (a) Bulk density; and (b) Total porosity of CEBs stabilized with 10\% CCR and containing fibres. 
Mostafa and Uddin [7] similarly reported that the value of bulk density decreased $(1,968-$ $1,947 \mathrm{~kg} / \mathrm{m}^{3}$ ) with banana fibres $(5 \%)$ for CEBs stabilized with $7 \%$ cement. However, these studies [7], [39] reported higher values of bulk density than the present study (1,690 to $1,565 \mathrm{~kg} / \mathrm{m}^{3}$ ). It can be related to the stabilization with cement which is heavier (specific density of 3.1) than the CCR (2.49) used in the present study. It can also be related to the water demand (16\% [39] and 10-12\% [7]) by the earthen material for the production of CEBs, and achieve maximum dry density, which was lower than $19 \%$ (present study). In fact, the more water is required by the earthen material, the more pores are created after drying and the lower is the bulk density of CEBs. The decrease of bulk density of CEBs with the incorporation of fibres can also be explained by the lower density of fibres (specific density of 1.09 for Okra fibre and 0.99 for polymer fibre) than the earthen material (specific density of 2.75), as well as the increase of total porosity (38-42\%). On the structural point of view, increasing the total porosity (decreasing the bulk density) of the materials is beneficial for reducing the dead load of a building.

However, the fractions of the total porosity which is accessible by water were in the ranges of $0.85-0.90(33-36 \%)$ and $0.75-0.85(33-35 \%)$ respectively for CEBs containing plant and polymer fibres (Table 1). This is equivalent to water absorption (WA) of 20-22\% after total saturation (Table 1), which is slightly higher than the recommended values of 15-20\% [40]. By contrast, the coefficient of capillary absorption was in the range of $10-15 \mathrm{~g} / \mathrm{cm}^{2} \cdot \mathrm{min}^{1 / 2}$ with plant and $10-20 \mathrm{~g} / \mathrm{cm}^{2} \cdot \mathrm{min}^{1 / 2}$ with polymer fibres (Table 1). It is slightly lower than $20 \mathrm{~g} / \mathrm{cm}^{2} \cdot \mathrm{min}^{1 / 2}$ for classification as very low capillary CEBs [38]. This is interesting for the resistance of CEBs masonry to capillary water rising through the foundation.

Table 1: Summary of the physical and thermal properties of CEBs stabilized with $10 \%$ CCR and containing fibres: Average values and coefficient of variations.

\begin{tabular}{|c|c|c|c|c|c|c|c|}
\hline \multirow{2}{*}{\multicolumn{2}{|c|}{$\begin{array}{c}\text { Fibre } \\
\text { content } \\
(\%)\end{array}$}} & \multicolumn{3}{|c|}{ Physical properties } & \multicolumn{3}{|c|}{ Thermal properties } \\
\hline & & $\begin{array}{l}\text { WAP } \\
(\%)\end{array}$ & WA $(\%)$ & $\begin{array}{c}\mathrm{Ca}_{10 \min } \\
\left(\mathrm{g} / \mathrm{cm}^{2} \cdot \mathrm{min}^{1 / 2}\right)\end{array}$ & $\begin{array}{l}\text { Effusivity } \\
\left(\mathrm{J} / \mathrm{m}^{2} \cdot \mathrm{K} \cdot \mathrm{s}^{1 / 2}\right)\end{array}$ & $\begin{array}{l}\text { Capacity } \\
(\mathrm{J} / \mathrm{kg} . \mathrm{K})\end{array}$ & $\begin{array}{c}\text { Penetration } \\
\text { depth (m) }\end{array}$ \\
\hline \multirow{5}{*}{ 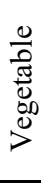 } & 0 & 332 & 201 & 104 & 11594 & 9161 & 0.1220 \\
\hline & 0.2 & $35 \quad 0$ & 212 & 116 & 10804 & 9084 & $0.117 \quad 0$ \\
\hline & 0.4 & $35 \quad 2$ & 222 & $11 \quad 10$ & 10553 & 8123 & $0.131 \quad 2$ \\
\hline & 0.8 & 361 & 222 & 135 & 9832 & 8850 & 0.1121 \\
\hline & 1.2 & $36 \quad 0$ & 221 & 1615 & 9533 & 9152 & $0.108 \quad 1$ \\
\hline \multirow{5}{*}{ 岕 } & 0 & 332 & 201 & 104 & 11594 & 9161 & 0.1220 \\
\hline & 0.2 & 327 & 206 & $15 \quad 19$ & $985 \quad 5$ & 9501 & $0.107 \quad 5$ \\
\hline & 0.4 & $34 \quad 0$ & 211 & 1623 & 9615 & 9422 & $0.103 \quad 5$ \\
\hline & 0.8 & $35 \quad 3$ & 214 & $15 \quad 19$ & 8828 & 9087 & 0.0997 \\
\hline & 1.2 & 354 & 222 & $20 \quad 17$ & $798 \quad 3$ & 10918 & $0.078 \quad 11$ \\
\hline
\end{tabular}

WAP: water accessible porosity, WA: water absorption, $\mathrm{Ca}_{10 \min }$ : coefficient of capillary absorption after 10 minutes.

For comparison, the WA of CEBs stabilized with $8 \%$ cement, compacted at high pressure $(10 \mathrm{MPa})$, increased in the range of $9-10.5 \%$ with $0-0.2 \%$ palm fibres [6]. Similarly, the WA evolved in the ranges of $8-16 \%, 8-15 \%$ and $8-14 \%$ for CEBs reinforced with $0-1 \%$ bagasse, coconut and oil palm fibres [9]. The WA of CEBs containing fibres is rarely studied [10]. However, its evolution points out the possibility of better regulating the hygrothermal performances in building, particularly with plant fibres given their natural affinity with water. Nevertheless, particular attention should be taken not to compromise the long-term durability 
of CEBs vis a vis the water absorption and bio-degradation. This can be achieved by reducing the water accessible porosity in future studies.

\subsection{Thermal effusivity and specific thermal capacity}

The thermal properties of stabilized CEBs were also affected by the incorporation of fibres. The incorporation of $0-1.2 \%$ fibre decreased the thermal effusivity in the range of 1,160 to $950 \mathrm{~J} / \mathrm{m}^{2} \cdot \mathrm{K} \cdot \mathrm{s}^{1 / 2}$ with plant and 1,160 to $800 \mathrm{~J} / \mathrm{m}^{2} \cdot \mathrm{K} \cdot \mathrm{s}^{1 / 2}$ with polymer fibres (Table 1 ). The thermal capacity evolved in the range of 810 and $915 \mathrm{~J} / \mathrm{kg} . \mathrm{K}$ with plant and 910 to $1,090 \mathrm{~J} / \mathrm{kg} . \mathrm{K}$ with polymer fibres, reaching the maximum values with $1.2 \%$ fibre content (Table 1). This suggests that increasing the fibre content decreases the thermal effusivity and increases the thermal capacity of CEBs. Table 1 further shows that the thermal effusivity and capacity recorded the same range of variability (coefficient of variation $<8$ ) for both types of fibres.

Similarly, the thermal effusivity of CEBs decreased from 1,365 to $1,000 \mathrm{~J} / \mathrm{m}^{2} \cdot \mathrm{K} \cdot \mathrm{s}^{1 / 2}$ and the thermal capacity increased from 1,015 to $1,372 \mathrm{~J} / \mathrm{kg} . \mathrm{K}$ with the addition of 0 to $8 \%$ sawdust [15]. The thermal capacity of $960-1,890 \mathrm{~J} / \mathrm{kg} . \mathrm{K}$ was reported for CEBs stabilized with $5 \%$ cement and containing $0-10 \%$ date palm fibres [41]. This confirms that the thermal effusivity tends to decrease with increasing fibre content while the thermal capacity increases. However, it is not very clear whether this evolution is directly related to the effect of fibres or if it is indirectly related to the decrease of bulk density and increase of porosity resulting from the incorporation of fibres (Section 3.1). This is due to the fact that similar evolution of thermal properties was previously related to the decrease of the bulk density for CEBs which do not contain fibres [13], [42], [43]. Therefore, there is still need to assess the effect of fibres on the thermal properties for CEBs which have constant bulk density by varying the compaction pressure.

\subsection{Thermal conductivity and thermal diffusivity}

The thermal conductivity of stabilized CEBs containing $0-1.2 \%$ fibres evolved in the range of 0.84 to $0.63 \mathrm{~W} / \mathrm{m} . \mathrm{K}$ with plant and 0.84 to $0.38 \mathrm{~W} / \mathrm{m} . \mathrm{K}$ with polymer fibres (Fig. 3(a)). The thermal diffusivity evolved in the range of $6.1 \mathrm{E}-7$ to $4.2 \mathrm{E}-7 \mathrm{~m}^{2} / \mathrm{s}$ with plant and $5.4 \mathrm{E}-7$

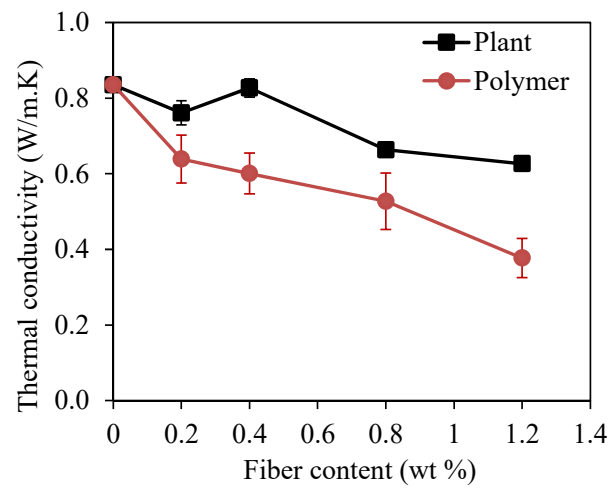

(a)

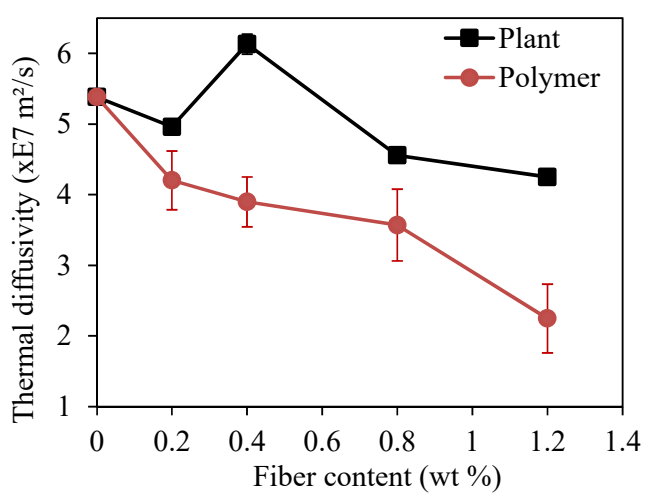

(b)

Figure 3: (a) Thermal conductivity; and (b) Thermal diffusivity of CEBs stabilized with $10 \%$ CCR and containing fibres. 
to $2.2 \mathrm{E}-7 \mathrm{~m}^{2} / \mathrm{s}$ with polymer fibres, reaching the minimum values with $1.2 \%$ fibre (Fig. $3(\mathrm{~b})$ ). Fig. 3 shows that both thermal conductivity and diffusivity of CEBs containing polymer fibres have higher variability (standard deviation) than the CEBs containing plant fibres. This can again be related to the difficulties of achieving homogeneous mixtures with fibres.

Furthermore, the thermal efficiency was assessed based on thermal penetration depth into the CEBs. This parameter related the thermal properties of CEBs for a period of 24 hours. The depth evolved in the range of 0.12 to $0.10 \mathrm{~m}$ and 0.12 to $0.07 \mathrm{~m}$, respectively, for CEBs containing $0-1.2 \%$ plant and polymer fibres (Table 1). This suggests that the thermal flux does not cross through the total thickness $(0.14 \mathrm{~m})$ of CEBs. Otherwise, the knowledge of thermal penetration depth would be useful for re-designing the most appropriate thickness of the CEBs for achieving the thermal efficiency of the wall.

Different studies clearly reported different values of thermal conductivity and diffusivity, but they all reported similar decreasing evolution with increasing content of fibres. For instance, Guettala et al. [39] reported that the thermal conductivity decreases (1.2$0.8 \mathrm{~W} / \mathrm{m} . \mathrm{K})$ with the increase of cock granules content $(0-12 \%)$ for CEBs stabilized with $12 \%$ cement. Similarly, the thermal conductivity and diffusivity of CEBs respectively decreased from 0.96 to $0.51 \mathrm{~W} / \mathrm{m} . \mathrm{K}$ and $3.3 \mathrm{E}-7$ to $2.1 \mathrm{E}-7 \mathrm{~m}^{2} / \mathrm{s}$ with the addition of 0 to $8 \%$ sawdust [15]. Similarly to the present study, this can partly be explained by the lower thermal conductivity and diffusivity of fibres (0.04-0.08 W/m.K for plant aggregates [10], $0.26 \mathrm{~W} / \mathrm{m} .{ }^{\circ} \mathrm{C}$ for okra fibres [32]), and the air trapped in the pores $(0.03 \mathrm{~W} / \mathrm{m} . \mathrm{K}$ and $2.2 \mathrm{E}-5 \mathrm{~m}^{2} / \mathrm{s}$ ). Therefore, it can be mentioned that the incorporation of fibres in CEBs increases the porosity and decreases the thermal transfer, i.e. increases the thermal inertia of CEBs. This may improve the indoor thermal comfort in warm regions of Burkina Faso. Nevertheless, in order to assess the direct contribution of okra and polymer fibres to the improvement of the hygrothermal properties of CEBs, their intrinsic thermal and hygroscopic properties need to be determined and compared with the properties of CEBs without fibres.

\subsection{Compressive strength CEBs}

Fig. 4 details the evolution of the average compressive strength, in dry and wet conditions, of stabilized CEBs containing fibres. The dry compressive strength decreased from 4.3 $\mathrm{MPa}$ with $0 \%$ fibre to a quasi-constant value of $3.7 \mathrm{MPa}$ with $0.2 \%$ plant fibre and 4.3 to $2.9 \mathrm{MPa}$ with $0.8 \%$ polymer fibre (Fig. 4(a)). Similarly, the wet compressive strength decreased from $2.7 \mathrm{MPa}$ with $0 \%$ fibre to $1.3 \mathrm{MPa}$ with $0.2 \%$ plant fibre and 2.7 to $1.7 \mathrm{MPa}$ with polymer fibre (Fig. 4(b)). Fig. 4(b) shows that the CEBs containing plant fibres recorded lower values of wet compressive strength than the CEBs containing polymer fibres. This is possibly related to the affinity of plant fibres for water. Thus, the CEBs containing fibres can only be useful for construction of non-load bearing wall which requires the compressive strength of $2 \mathrm{MPa}$ and $1 \mathrm{MPa}$ respectively in dry and wet conditions [44].

Furthermore, the coefficient of structural efficiency (CSE) was evaluated as the ratio between the dry compressive strength and bulk density of CEBs. The CSE of stabilized CEBs containing $0-1.2 \%$ fibre decreased in the range of 2,500 to $2,200 \mathrm{~Pa} \cdot \mathrm{m}^{3} / \mathrm{kg}$ with plant fibres and 2,500 to $1,800 \mathrm{~Pa} \cdot \mathrm{m}^{3} / \mathrm{kg}$ with polymer fibres. For structural applications, the aim would be to maximize the resistance (strength) and minimize the weight (density) of the materials in order to increase the CSE and improve the carrying capacity. Thus, this confirms that stabilized CEBs containing fibres are useful in non-load bearing applications such as in low rising one-storey building or as fill masonry in partition wall. 


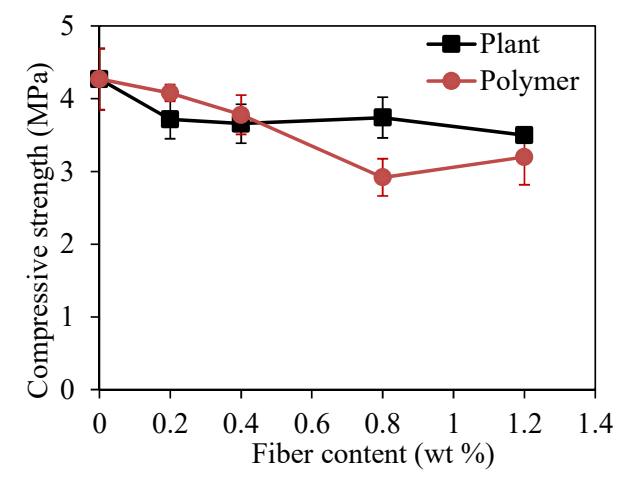

(a)

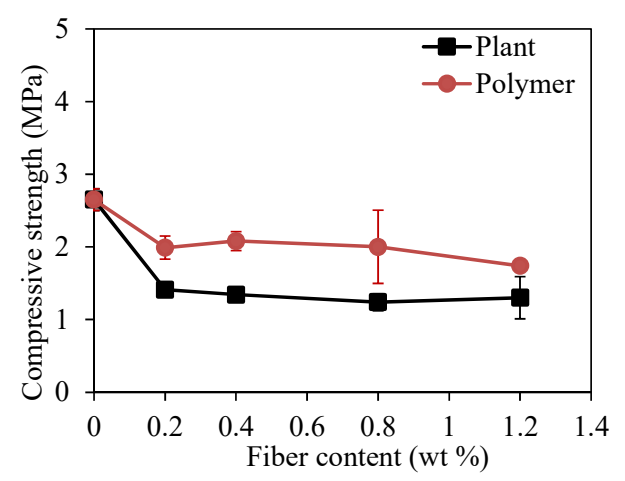

(b)

Figure 4: Compressive strength in (a) Dry; and (b) Wet conditions of CEBs stabilized with $10 \% \mathrm{CCR}$ and containing fibres.

Some studies similarly reported the decrease of the compressive strength of CEBs containing fibres. For instance, Taallah and Guettala [5] reported that the compressive strength of CEBs stabilized with $10 \%$ lime decreased from 7.9 to $7 \mathrm{MPa}$ with incorporation of 0 to $0.2 \%$ palm fibres. Similar evolution was observed for wet compressive strength [5]. Note that the absolute values of the compressive strength reported by these authors [5] cannot be directly compared to the values reported in the present study, given that the former CEBs were compacted at higher pressure (15 MPa). Guettala et al. [39] reported the decreasing values of compressive strength (3-2 MPa) with increasing content of cock granules $(0-12 \%)$ for CEBs compacted at normal pressure $(2.5 \mathrm{MPa})$, which is rather comparable to the present study. The decrease of the compressive strength with increasing fibre content was related to the low adhesion between the fibres and the matrix of CEBs [5]. This adhesion not only depends on the type, content and length of fibres, but also the type of earthen material.

By contrast, Donkor and Obonyo [8] reported that the compressive strength of CEBs slightly increased to reach the maximum value with $0.4 \%$ polypropylene fibre. Similarly, Danso et al. [9] reported slight increase of the compressive strength from $2 \mathrm{MPa}$ to $3 \mathrm{MPa}$ with $0.5 \%$ bagasse, coconut and oil palm fibres for CEBs compacted at high pressure $(10 \mathrm{MPa})$. The difference in the reported values and evolutions of compressive strength of CEBs can be related to the types and contents of chemical stabilizers or types and length of fibres as well as the methods of production and testing. For instance, Mostafa and Uddin [7] tested the compressive strength of CEBs on single prismatic sample which has size of $120 \times 120 \times 90 \mathrm{~mm}$. This cannot be directly compared to the results obtained with testing on double stack of sample (140 x $140 \times 90 \mathrm{~mm})$ of CEBs in the present study, as recommended by the XP P13-901 standard [38]. Further studies should be carried out to assess the effect of varying the content and length of fibres on the mechanical properties of CEBs.

\section{CONCLUSION}

Fibres from by-products of okra plant and polymer sachet, otherwise considered wastes, are useful for improving the thermophysical properties of CEBs. Throughout this study, the following conclusions were reached about stabilized CEBs containing fibres:

- The incorporation of fibres $(0-1.2 \%)$ decreased the bulk density $\left(1,690-1,565 \mathrm{~kg} / \mathrm{m}^{3}\right)$ and increased the total porosity $(38-42 \%)$ of stabilized CEBs. The fraction of the total 
porosity accessible by water was $0.85-0.90(33-36 \%)$ with plant fibres and $0.75-0.85$ (33-35\%) with polymer fibres. This is equivalent to water absorption by total saturation of $20-22 \%$, which is unfortunately slightly higher than the prescribed values of $15-20 \%$. However, the coefficient of capillary absorption was smaller than $20 \mathrm{~g} / \mathrm{cm}^{2} \cdot \mathrm{min}^{1 / 2}$ for very low capillary absorption.

- The fibres decreased the thermal effusivity and increased the thermal capacity of CEBs. This resulted in the decrease of thermal conductivity $(0.84$ to $0.63 \mathrm{~W} / \mathrm{m} . \mathrm{K}$ and 0.84 to $0.38 \mathrm{~W} / \mathrm{m} . \mathrm{K})$ and diffusivity $\left(6.1 \mathrm{E}-7\right.$ to $4.2 \mathrm{E}-7 \mathrm{~m}^{2} / \mathrm{s}$ and $5.4 \mathrm{E}-7$ to $2.3 \mathrm{E}-7 \mathrm{~m}^{2} / \mathrm{s}$ ), respectively, with 0 to $1.2 \%$ plant and polymer fibres. It was accompanied by the decrease of the depth $(0.12-0.07 \mathrm{~m})$ of the penetration of thermal flux in CEBs. This could allow a double application of thermal mass and low thermal conductivity for wall insulation.

- The incorporation of $0-1.2 \%$ fibres reduced the structural capacity of CEBs, decreasing the dry and wet compressive strength (4.3-2.9 MPa and 2.7-1.3 MPa). Nevertheless, they are useful for construction of non-load bearing or partition walls.

Although, the by-product fibres are beneficial for lightening and improving the thermal properties of CEBs, the higher fraction of porosity accessible to water may be detrimental to their durability. Particular attention should be taken not to compromise the durability of CEBs in contact with water in the long term, while taking advantages of their hygrothermal performances. Future studies should assess the intrinsic thermal properties of okra fibres for possible applications as isolation in buildings. The effect of varying the length of fibres should also be assessed to establish the law of mixture that governs their behaviour in earth-based composites.

\section{ACKNOWLEDGEMENTS}

"Académie de la Recherche et de l'Enseignement Supérieur" of the "Fédération WallonieBruxelles (Belgium) - Commission de la Coopération au Développement" (ARES-CCD) provided the financial support as part of an international research and development project "Amélioration de la qualité de l'habitat en terre crue au Burkina Faso/Improving the quality of earth-based habitats in Burkina Faso PRD2016-2021". Andy AZIABLE, a former MSc student at Institute 2iE, and Burkina Industrial Gas (BIG) are acknowledged for respectively contributing in the collection of experiment data and generously providing the CCR. The first author thanks the anonymous reviewers and F. Ntimugura (University of Exeter) for largely improving the quality of original manuscript.

\section{REFERENCES}

[1] Millogo, Y. et al., How properties of Kenaf fibers from Burkina Faso contribute to the reinforcement of earth blocks. Materials (Basel), 8, pp. 2332-2345, 2015.

[2] Binici, H., Aksogan, O. \& Shah, T., Investigation of fibre reinforced mud brick as a building material. Constr. Build. Mater., 19, pp. 313-318, 2005.

[3] Ojo, E.B. et al., Effects of fibre reinforcements on properties of extruded alkali activated earthen building materials. Constr. Build. Mater. 227, 116778, 2019.

[4] Laibi, A. et al., Physicochemical and mechanical characterization of Benin's Kenaf fibers and its effect on the building compressed earth blocks (CEB) mechanical properties. Res. J. Chem. Sci., 7, pp. 6-15, 2017.

[5] Taallah, B. \& Guettala, A., The mechanical and physical properties of compressed earth block stabilized with lime and filled with untreated and alkali-treated date palm fibers. Constr. Build. Mater., 104, pp. 52-62, 2016. 
[6] Taallah, B. et al., Mechanical properties and hygroscopicity behavior of compressed earth block filled by date palm fibers. Constr. Build. Mater., 59, pp. 161-168, 2014.

[7] Mostafa, M. \& Uddin, N., Experimental analysis of compressed earth block (CEB) with banana fibers resisting flexural and compression forces. Case Stud. Constr. Mater., 5, pp. 53-63, 2016.

[8] Donkor, P. \& Obonyo, E., Earthen construction materials: Assessing the feasibility of improving strength and deformability of compressed earth blocks using polypropylene fibers. Mater. Des., 83, pp. 813-819, 2015.

[9] Danso, H. et al., Physical, mechanical and durability properties of soil building blocks reinforced with natural fibres. Constr. Build. Mater., 101, pp. 797-809, 2015.

[10] Laborel-Préneron, A. et al., Plant aggregates and fibers in earth construction materials: A review. Constr. Build. Mater., 111, pp. 719-734, 2016.

[11] Ashour, T. et al., Thermal conductivity of unfired earth bricks reinforced by agricultural wastes with cement and gypsum. Energy Build., 104, pp. 139-146, 2015.

[12] Van Damme, H. \& Houben, H., Earth concrete. Stabilization revisited. Cem. Concr. Res., 114, pp. 90-102, 2018.

[13] Moussa, S.H. et al., Comparative study of thermal comfort induced from masonry made of stabilized compressed earth block vs conventional cementitious material. $J$. Miner. Mater. Charact. Eng., 7, pp. 385-403, 2019.

[14] Hema, C.M. et al., Vernacular housing practices in Burkina Faso: Representative models of construction in Ouagadougou and walls hygrothermal efficiency. Energy Procedia, Elsevier: Lausanne, pp. 535-540, 2017.

[15] Boro, D., Florent Kieno, P. \& Ouedraogo, E., Experimental study of the thermal and mechanical properties of compressed earth blocks stabilized with sawdust according to the rates for the thermal insulation of a building. Int. J. Constr. Eng. Manag., 6, pp. 103-109, 2017.

[16] Araya-Letelier, G. et al., Influence of natural fiber dosage and length on adobe mixes damage-mechanical behavior. Constr. Build. Mater., 174, pp. 645-655, 2018.

[17] Millogo, Y. et al., Experimental analysis of pressed adobe blocks reinforced with hibiscus cannabinus fibers. Constr. Build. Mater., 52, pp. 71-78, 2014.

[18] Prasad, C.K.S., Nambiar, E.K.K. \& Abraham, B.M., Plastic fibre reinforced soil blocks as a sustainable building material. Int. J. Adv. Res. Technol., 1, pp. 1-4, 2012.

[19] Villamizar, M.C.N. et al., Effect of the addition of coal-ash and cassava peels on the engineering properties of compressed earth blocks. Constr. Build. Mater., 36, pp. 276286, 2012.

[20] Elenga, R.G. et al., Characterization of clayey soils from Congo and physical properties of their compressed earth blocks reinforced with post-consumer plastic wastes. Geomaterials, 1, pp. 88-94, 2011.

[21] Laibi, A.B. et al., Influence of the kenaf fiber length on the mechanical and thermal properties of compressed earth blocks (CEB). KSCE J. Civ. Eng., 22, pp. 785-793, 2018.

[22] Danso, H. et al., Effect of fibre aspect ratio on mechanical properties of soil building blocks. Constr. Build. Mater., 83, pp. 314-319, 2015.

[23] Mostafa, M. \& Uddin, N., Effect of banana fibers on the compressive and flexural strength of compressed earth blocks. Buildings, 5, pp. 282-296, 2015.

[24] Galan-Marin, C., Rivera-Gomez, C. \& Petric, J., Clay-based composite stabilized with natural polymer and fibre. Constr. Build. Mater., 24, pp. 1462-1468, 2010.

[25] Nshimiyimana, P. et al., Calcium carbide residue and rice husk ash for improving the compressive strength of compressed earth blocks. MRS Adv., 3, pp. 2009-2014, 2018. 
[26] Nshimiyimana, P. et al., Effect of production and curing conditions on the performance of stabilized compressed earth blocks: Kaolinite vs quartz-rich earthen material. MRS Adv., 5, pp. 1277-1283, 2020.

[27] De Rosa, I.M. et al., Morphological, thermal and mechanical characterization of okra (Abelmoschus esculentus) fibres as potential reinforcement in polymer composites. Compos. Sci. Technol., 70, pp. 116-122, 2010.

[28] Alam, M.S. \& Khan, G.M., Chemical analysis of okra bast fiber (Abelmoschus Esculentus) and its physico-chemical properties. J. Text. Apparel. Technol. Manag., 5, pp. 1-9, 2007.

[29] Khan, G.M.A., Yilmaz, N.D. \& Yilmaz, K., Effects of chemical treatments and degumming methods on physical and mechanical properties of okra bast and corn husk fibers. J. Text. Inst., pp. 1-18, 2019.

[30] Khan, G.M.A., Yilmaz, N.D. \& Yilmaz, K., Okra fibers: Potential material for green biocomposites. Green Biocomposites: Design and Applications, eds M. Jawaid, M.S. Salit \& O.Y. Alothman, Springer International Publishing, pp. 261-284, 2018.

[31] Khan, G.M.M. et al., Grafting of acrylonitrile monomer onto bleached okra bast fibre and its textile properties. Indian J. Fibre Text. Res., 34, pp. 321-327, 2009.

[32] Duman, M.N. et al., Nonwoven production from agricultural okra wastes and investigation of their thermal conductivities. IOP Conf. Ser. Mater. Sci. Eng., 254, pp. $1-7,2017$.

[33] Grellier, C., Pure water plastic bags inspire recycling in Africa. Makery, 2017. www.makery.info/en/2017/04/25/les-sacs-plastique-pure-water-inspirent-lerecyclage-en-afrique/.

[34] Nshimiyimana, P. et al., Physico-chemical and mineralogical characterization of clay materials suitable for production of stabilized compressed earth blocks. Constr. Build. Mater., 241, pp. 1-13, 2020.

[35] CDE, CRATerre-EAG \& ENTPE, Compressed Earth Blocks: Testing Procedures Guide, Technology Series No. 16, CDE (ARSO): Brussels, Belgium, 2000.

[36] Nshimiyimana, P. et al., Chemico-microstructural changes in earthen building materials containing calcium carbide residue and rice husk ash. Constr. Build. Mater., 216, pp. 622-631, 2019.

[37] AFNor, NF P 18-459: Essai pour béton durci - Essai de porosité et de masse volumique, Saint-Denis La Plaine Cedex, 2010.

[38] AFNor, XP P13-901: Blocs de terre comprimée pour murs et cloisons, DéfinitionsSpécifications-Méthodes d'essais-Conditions de réception. Saint-Denis La Plaine Cedex, 2001.

[39] Guettala, S., Bachar, M. \& Azzouz, L., Properties of the compressed-stabilized earth brick containing cork granules. J. Earth Sci. Clim. Chang., 7, 2016. DOI: $10.4172 / 2157-7617$.

[40] Guettala, A., Abibsi, A. \& Houari, H., Durability study of stabilized earth concrete under both laboratory and climatic conditions exposure. Constr. Build. Mater., 20, pp. 119-127, 2006.

[41] Berrehail, T., Zemmouri, N. \& Agoudjil, B., Thermal conductivity of cement stabilized earth bricks reinforced with date palm fiber. AIP Conf. Proc., 1968.

DOI: $10.1063 / 1.5039223$.

[42] Sore, S.O. et al., Stabilization of compressed earth blocks (CEBs) by geopolymer binder based on local materials from Burkina Faso. Constr. Build. Mater., 165, pp. 333-345, 2018. 
[43] Mansour, M.B. et al., Optimizing thermal and mechanical performance of compressed earth blocks (CEB). Constr. Build. Mater., 104, pp. 44-51, 2016.

[44] CDI\&CRATerre, Compressed Earth Blocks - Standards, Guide Technologies Series No. 11, Brussels, 1998. 